\title{
Smoothing of Slug Tests for Laboratory Scale Aquifer Assessment-A Comparison among Different Porous Media
}

\author{
Francesco Aristodemo ${ }^{1, *}$, Agostino Lauria ${ }^{1}$, Giuseppe Tripepi ${ }^{1}$, \\ Maria Fernanda Rivera-Velasquéz ${ }^{2}$ and Carmine Fallico ${ }^{1}$ (D) \\ 1 Dipartimento di Ingegneria Civile, Università della Calabria, via P. Bucci, cubo 42B, \\ 87036 Arcavacata di Rende (CS), Italy \\ 2 Universidad Nacional de Chimborazo, Facultad de Ingeniería, Avenida Antonio José de Sucre, \\ EC060104 Riobamba, Ecuador \\ * Correspondence: francesco.aristodemo@unical.it; Tel.: +39-(0)9-8449-6554
}

Received: 25 June 2019; Accepted: 27 July 2019; Published: 29 July 2019

\begin{abstract}
A filtering analysis of hydraulic head data deduced from slug tests injected in a confined aquifer with different porous media is proposed. Experimental laboratory tests were conducted in a large-scale physical model developed at the University of Calabria. The hydraulic head data were deduced from the records of a pressure sensor arranged in the injection well and subjected to a processing operation to filter the high-frequency noise. The involved smoothing techniques are the Fourier transform and two types of wavelet transform. The performances of the filtered hydraulic heads were examined for different slug volumes and four model layouts in terms of optimal fitting of the Cooper's analytical solution. The hydraulic head variations in the confined aquifer were analyzed using wavelet transform in order to discover their energy contributions and frequency oscillations. Finally, the raw and smoothed hydraulic heads were adopted to calculate the hydraulic conductivity of the aquifer.
\end{abstract}

Keywords: slug tests; hydraulic head; porous media; filtering; wavelet analysis; hydraulic conductivity

\section{Introduction}

The slug tests can be considered the most currently used field tests for the estimation of hydrodynamic parameters characterizing an aquifer. These tests are often preferred to traditional pumping tests due to the ease of execution, low costs, particularly in investigations of contaminated aquifers, and for the reduced volume of porous medium involved in the measurements, although pumping tests are generally considered more reliable and less subject to errors and uncertainties [1-7].

The slug tests consist of the detection of hydraulic head variations induced by a rapid extraction or displacement of a known water mass in the well and recorded until the initial equilibrium conditions are reached. The hydraulic head values obtained by these tests allow the determination of the hydraulic conductivity values $(k)$ and, under certain conditions, also the storage coefficient $(S)$ [1,8-13]. Yang and Yeh [14] and Cardiff et al. [15] report a very interesting historical overview of the background concerning slug tests, and, in any case, this subject is very common in the scientific literature.

Numerous topics linked to the slug tests were widely analyzed and investigated. However, further investigations are still possible on some aspects related to slug tests, such as the management of wide data sets.

Some scientists, such as Chapuis [16] and Abellan and Noetinger [17], have already addressed this topic, highlighting the difficulty to manage large data sets given by slug tests and to select the quantity 
of information that may be obtained from a test. Nevertheless, innovative works to this subject can be produced, investigating the influence deriving from an adequate data smoothing analysis, as recently shown by Aristodemo et al. [18].

For slug tests, the recording of time-varying hydraulic head data must be performed with appropriate instruments such as electronic pressure sensors able to acquire data with a certain measurement frequency (e.g., [3]). If the measurement frequency is relevant, problems arise from the occurring high-frequency noise and the increasing computational cost to process the pressure data. Conversely, if the measurement frequency is limited, particularly at laboratory scale, there is the risk that the input information is not able to correctly catch the physical phenomenon as in the case of the occurrence of local non-linear effects in the hydraulic head (e.g., [19]). In a previous study [18] it has been highlighted that the measurement frequency $f=100 \mathrm{~Hz}$ proves to be a suitable value allowing to maintain the quality of the acquired time series of pressure in terms of global and local energy contents and frequency oscillations. Moreover, it should be noted that the quality of the data assumes a fundamental role in the characterization of the aquifers. Indeed, input data can have systematic and random errors, phenomena of errors propagation or environmental noise attributable to different reasons (e.g., $[5,20])$.

During experimental campaigns, particularly at laboratory scale, the elimination of unwanted noise in the recorded raw data is an important issue in different scientific disciplines. Specifically, filtering methods such as decimation, convolution equations, polynomial approximations, moving average filters, and spectral approaches were adopted [21-33]. In this context, Viovy et al. [34] stated that the smoothing operation can lead to a minimization of the uncertainty of the involved input data. Therefore, it is fundamental to choose a smoothing method with a certain prudence since each filtering approach can present potential drawbacks $[27,35]$. It was already underlined the opportunity to provide a smoothing for cases in which the data sets deduced from slug test are specifically heavy. For this reason, Aristodemo et al. [18] have recently provided a methodology to filter high-frequency disturbance in the time series of hydraulic heads, giving useful information regarding the specific smoothing approaches.

The goal of the present work is to verify and extend the results obtained by Aristodemo et al. [18] for various porous media characterizing the aquifer by means of slug tests. This analysis refers to a laboratory campaign executed on a 3D model of a confined aquifer and developed in the GMI (Grandi Modelli Idraulici) Laboratory of the University of Calabria. During the laboratory investigation, four different types of porous media characterizing the saturated layer of the aquifer were taken into account. The slug tests were carried out by injecting a defined water mass in the central well of the groundwater system where a pressure sensor was placed to determine the hydraulic head variation $(h)$. Then, smoothing methods with working principles in frequency (a Fourier transform) and time-frequency domain (Mexican hat and Morlet wavelet transforms) (e.g., [36,37]) were applied to eliminate the high-frequency disturbance in the raw time series of $h$. For this purpose, ad-hoc cut-off frequencies were selected for data filtering adopting the mentioned approaches. In order to fit the reference Cooper's equation well [9], limits and capabilities of the involved smoothing approaches were checked through the calculation of the correlation coefficient and relative error for all model layouts, i.e., the porous media. The energy and the frequency oscillations of the time series of hydraulic head were exploited in the time-frequency domain through wavelet transform. Moreover, the raw and smoothed hydraulic heads given by the mentioned methods were adopted to calculate the hydraulic conductivity for the different porous media constituting the aquifer.

This study is presented in the following manner. Section 2 illustrates the experimental layout of the aquifer, the adopted porous media and the execution of the laboratory tests. Section 3 describes the methodology used to estimate the hydraulic conductivity and the approaches to smooth the raw values of the hydraulic heads.

Subsequently, the raw and smoothed time series of the hydraulic head are inspected in Section 4 through the comparison of the limits and capabilities of the smoothing methods to reproduce the 
Cooper's equation and to calculate the hydraulic conductivity. Section 5 recalls the main parts of the proposed approach and the results obtained.

\section{Laboratory Tests}

\subsection{Experimental Set-Up}

In the GMI Laboratory of the Department of Civil Engineering of the University of Calabria a physical model, reproducing 3D homogeneous and confined aquifer, was developed, within a metal box with dimensions $2 \mathrm{~m} \times 2 \mathrm{~m} \times 1 \mathrm{~m}$ (Figure 1a). Inside this sandbox, along the whole perimeter, at a distance of $5 \mathrm{~cm}$ from the walls, a perimetric chamber was built, by means of a metallic mesh sustained by vertical metallic supports and coated with a geotextile layer, to ensure the boundary condition of a given hydraulic head. For accomplishing slug tests and for the acquisition of hydraulic head data, an injection well and nine observation wells (piezometers) were inserted into the aquifer, with the disposal shown in Figure 1b. All the wells, made using pipes of polyvinyl chloride (PVC), with a diameter of $2.8 \mathrm{~cm}$, were completely penetrating, with openings on the pipe walls throughout the thickness of the aquifer. The whole was then covered with geo-textile, to avoid sand entry into the well. The injection well was central, while those of observation were located in various directions and at increasing distances from the injection well, to prevent influencing the flow in the porous medium (see Figure $1 \mathrm{~b}$ ). The porous material constituting the confined aquifer, with an assigned thickness, was placed on the bed of the metal box (see lateral section 1-1' sketched in Figure 1c).

a)

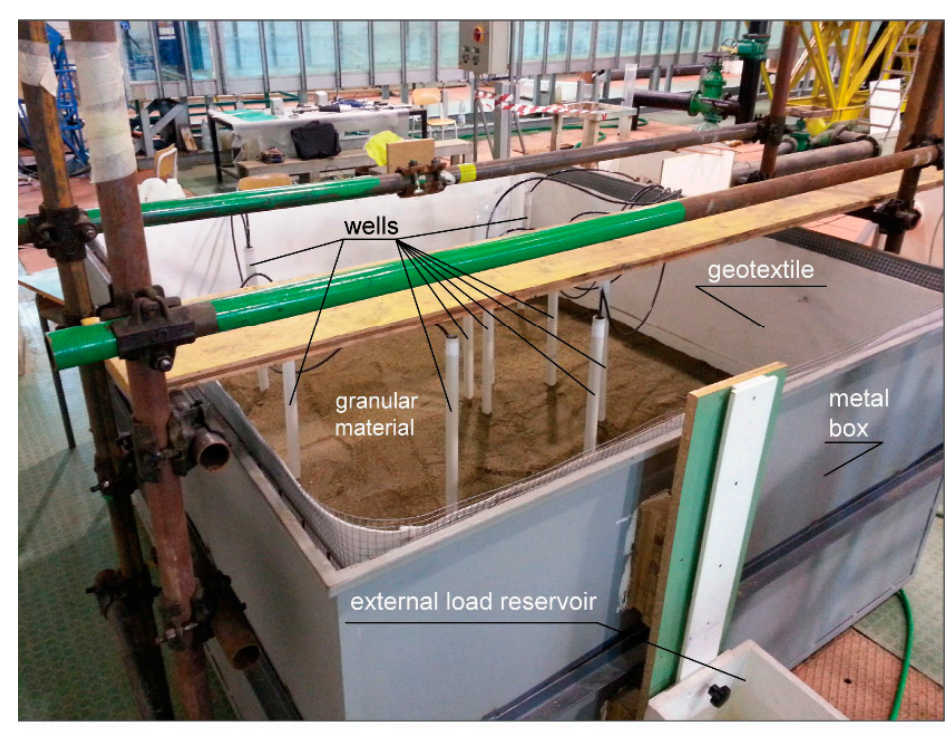

(b) : injection well

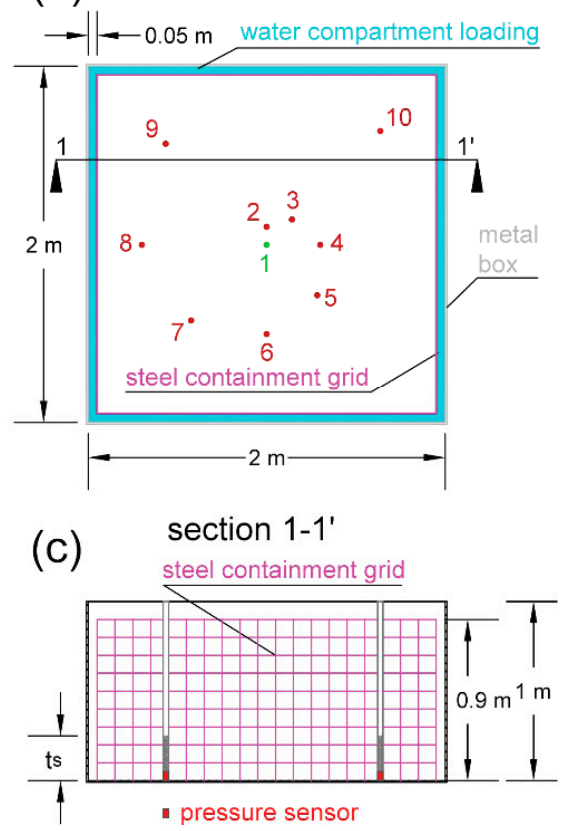

Figure 1. (a) View of the physical model of the 3D confined aquifer; (b) plan view of the placement of the injection and observation wells; (c) section 1-1' with the arrangement of the pressure sensors in the wells.

\subsection{Materials}

Inside the sandbox four different model layouts were realized, all related to the confined aquifer, but with different porous media constituting the aquifer, with the aim of verifying the results of the smoothing analysis for different characteristics of the solid matrix of the saturated layer.

Each aquifer constituted in this way, even if granulometrically homogeneous, due to the random arrangement of the grains of the solid matrix, shows various pore size, and then it can be considered 
heterogeneous. Indeed, at the particular scale of investigation, the porous medium heterogeneity influences the flow phenomena, certainly due to the presence of micro and macro pores, but probably also because it begins to suffer from the greater or lesser interconnection of the pores in which the water flow occurs $[38,39]$. Table 1 shows the values of the granulometric analysis carried out on the porous media considered.

Table 1. Content of clay, silt, sand and gravel for the four porous media constituting the confined aquifer.

\begin{tabular}{ccccc}
\hline Textural Classes & $\begin{array}{c}\text { I Model Layout } \\
\mathbf{( \% )}\end{array}$ & $\begin{array}{c}\text { II Model Layout } \\
\mathbf{( \% )}\end{array}$ & $\begin{array}{c}\text { III Model Layout } \\
\mathbf{( \% )}\end{array}$ & $\begin{array}{c}\text { IV Model Layout } \\
\mathbf{( \% )}\end{array}$ \\
\hline Gravel & 12.01 & 27.70 & 23.90 & 22.50 \\
Sand & 87.39 & 71.00 & 61.00 & 56.10 \\
Silt & 0.60 & 1.30 & 15.10 & 16.40 \\
Clay & - & - & - & 5.00 \\
\hline
\end{tabular}

As shown in Table 1, the largest percentage of gravel is related to the II model layout, while the minimum to the model layout I. The maximum percentage of sand is related to the model layout I and the minimum percentage to the model layout IV. The percentage of silt is maximum at the model layout IV and is minimal at the model layout I. The clay is absent in all porous media considered, except in the model layout IV, where it has a very low percentage. Figure 2 shows the granulometric curves relating to the four soils taken into consideration. The laying of these materials was performed by repeating different water loading and unloading cycles to reach a natural packing.

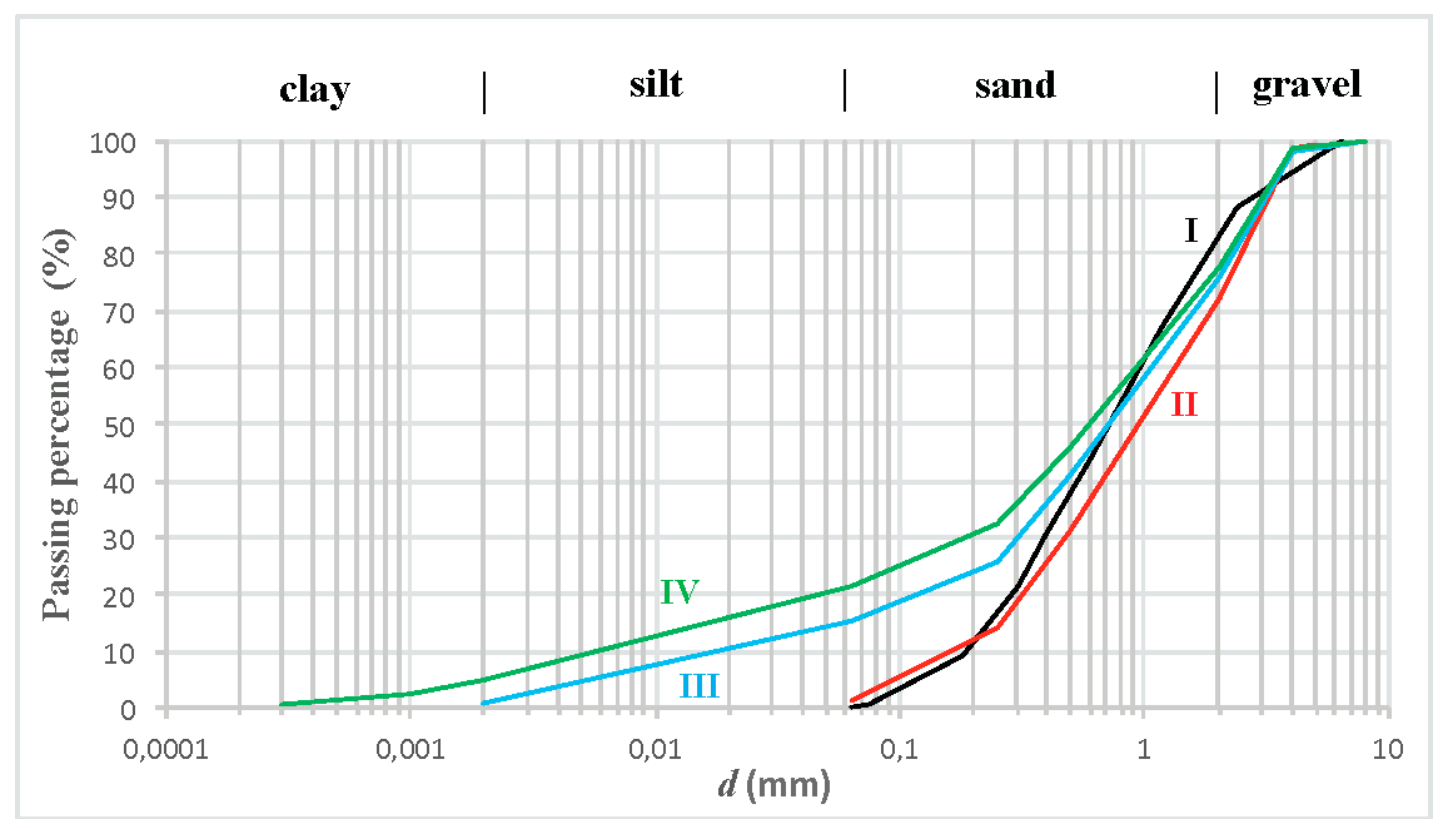

Figure 2. Granulometric curves of the four porous media taken into account.

\subsection{Tests Execution}

The values of the confined aquifer thickness and the undisturbed hydraulic head related to the injection well for each model layout are shown in Table 2. 
Table 2. Values of aquifer thickness and undisturbed hydraulic heads, determined by the bottom of the sandbox, for each of the four model layouts considered.

\begin{tabular}{ccc}
\hline Model Layout & Aquifer Thickness (m) & Undisturbed Hydraulic Heads (m) \\
\hline I & 0.25 & 0.38 \\
II & 0.25 & 0.32 \\
III & 0.25 & 0.32 \\
IV & 0.22 & 0.35 \\
\hline
\end{tabular}

Several slug tests were carried out, for each model layout, using the following injection volumes: $V=30 \mathrm{~mL}, 40 \mathrm{~mL}, 50 \mathrm{~mL}, 60 \mathrm{~mL}, 70 \mathrm{~mL}, 80 \mathrm{~mL}$ and $90 \mathrm{~mL}$ in the central well.

These volumes were assumed after verifying that, with their injection into the central well (about $1 \mathrm{~s})$, the variation of the hydraulic heads does not reach the sandbox walls and does not alter the fixed boundary conditions. Compliance with the boundary conditions was verified for each slug test carried out by measuring the hydraulic heads in the observation wells. Furthermore, between one test and the next, the complete restoration of the initial loading conditions was always ascertained. Note that, for model layout II, the slug tests with $V=30 \mathrm{~mL}$ and $40 \mathrm{~mL}$ were not executed.

In each well the pressure was measured by a submersible sensor (PDCR1830 model by Druck) (for more details, see $[40,41]$ ) using a measurement frequency of $100 \mathrm{~Hz}$, as suggested by Aristodemo et al. [18]. All sensors were located at the bed of the metal box (see Figure 1c). Although the monitoring of hydraulic heads was carried out in all piezometers, the smoothing modeling and the determination of the hydraulic conductivity will be performed considering only the pressure data recorded in the well subjected to the water insertion.

\section{Methods}

\subsection{Determination of Aquifer Hydraulic Conductivity}

The method of Cooper et al. [9] was used for the analysis of all the slug tests performed on the laboratory device described above and for each of the four model layouts considered. This is based on a type of curve matching, allowing estimation of the hydraulic conductivity and the specific storage coefficient of the aquifer. The relationships describing this method are as follows:

$$
\frac{\partial^{2} h}{\partial r^{2}}+\frac{1}{r} \frac{\partial h}{\partial r}=\frac{S_{s}}{K_{r}} \frac{\partial h}{\partial t}
$$

which meets the following boundary conditions:

$$
\begin{gathered}
h(r, 0)=0, r_{w}<r<\infty \\
H(0)=H_{0} \\
h(\infty, t)=0, t>0 \\
h\left(r_{w}, t\right)=H(t), t>0 \\
2 \pi r_{w} K_{r} B \frac{\partial h\left(r_{w}, t\right)}{\partial r}=\pi r_{c}^{2} \frac{S_{s}}{k_{r}} \frac{d H(t)}{d t}, t>0
\end{gathered}
$$

where $h$ is the variation of the hydraulic head from the static conditions $(\mathrm{L}), k_{r}$ is the radial component of the hydraulic conductivity $\left(\mathrm{LT}^{-1}\right), S_{s}$ the specific storage $\left(\mathrm{L}^{-1}\right), B$ the aquifer thickness $(\mathrm{L}), H$ the variation of the hydraulic head in well from the static conditions $(\mathrm{L}), H_{0}$ the initial variation of the hydraulic head in well $(\mathrm{L}), r_{w}$ the effective radius of well screen $(\mathrm{L}), r_{c}$ the effective radius of well casing (L), $r$ the radial direction (L) and $t$ the time (L). The boundary conditions (2) and (3) state that initially the variation of hydraulic head is zero everywhere outside the well and equal to $H_{0}$ inside the 
well. The boundary condition (4) states that as $r$ approaches infinity the variation in hydraulic head approaches zero. The boundary condition (5) states that after the first instant the hydraulic head in the aquifer at the face of the well is equal to that in the well. The relationship (6) expresses the fact that the rate of flow of water into (or out of) the aquifer is equal to the rate of decrease (or increase) in volume of water within the well. This mathematical model is based on the following assumptions: homogeneous formation, Darcian flow, instantaneous slug injection and negligible well losses [1,9].

This method allows also estimation of the specific storage coefficient, albeit with considerable uncertainty, as evidenced by many authors $[1,9,16,42-44]$.

\subsection{Smoothing Methods}

\subsubsection{Fourier Transform}

The Fourier analysis is a famous mathematical approach that allows for the decomposition of a waveform, i.e., an input signal, into an alternative representation characterized by sinusoidal components of different frequencies. This approach is fundamental for the characterization of the energy content in the frequencies domain, by transforming the involved function from a time-based point of view to a frequency-based one. The Fourier transform (FT) of a given data signal $x(t)$ is defined by:

$$
X(\omega)=\int_{-\infty}^{+\infty} x(t) e^{-i \omega t} d t
$$

in which $\omega$ (angular frequency) $=2 \pi f\left(\mathrm{~T}^{-1}\right), f$ is the frequency $\left(\mathrm{T}^{-1}\right)$ and $i$ is root square of -1 .

However, the difficulty of analysing signals with certain characteristics in the Fourier space has been highlighted [45]. Indeed, since the constitutive elements of the FT are trigonometric functions, the FT is particularly appropriate for analyzing stationary signals. The FT is, therefore, a powerful method for processing signals that can be expressed as a sum of sines and cosines, but is less useful when the signal is non-stationary. Furthermore, when transforming to the frequency domain with the FT, time information is lost and it is impossible to know the instant when a particular event occurs [46]. A low-pass filter will be adopted here by selecting a specific cut-off frequency, $f_{c}$, to eliminate the unwanted high-frequency noise occurring in the time variation of the raw values of $h$.

\subsubsection{Wavelet Transform}

The Wavelet transform (WT) is normally applied to analyze data with non-stationary energy contributions at different frequencies (e.g., [47]). In the wavelet framework, the basic functions present a finite spatial support, allowing for a local assessment of the signal. The localized functions adopted for the transform are deduced from scaling and shifting a basic function named mother wavelet, $\psi$ :

$$
\psi_{a b}(t)=\frac{1}{\sqrt{a}} \psi\left(\frac{t-b}{a}\right)
$$

where $a \in R e^{+}$is the parameter to scale in frequency the wavelet and $b \in R e$ is the parameter scale to shift in time the wavelet. A mother wavelet can be used for the integral wavelet transform only if it shows an inversion equation. This property is given by the so-called admissibility condition (for more details, see [37]).

Different mother wavelets were developed in the wavelet context. The selection of a characteristic mother wavelet is given by the similarity of the shape of the wavelet with the input time series of the considered data and if the involved phenomenon is characterized by a specific dynamics (e.g., [48]). Because of their large use in dynamic flow problems [49-51], Mexican hat and Morlet wavelets are here selected heuristically. 
The first used mother function is given by the Marr wavelet, also noted for its shape as the Mexican hat, mathematically expressed by the negative Laplacian of a Gaussian function:

$$
\psi(t)=\frac{2}{\sqrt{3}} \pi^{-1 / 4}\left(1-t^{2}\right) e^{-\frac{t^{2}}{2}}
$$

The shape of the Mexican hat wavelet is given in Figure 3a.
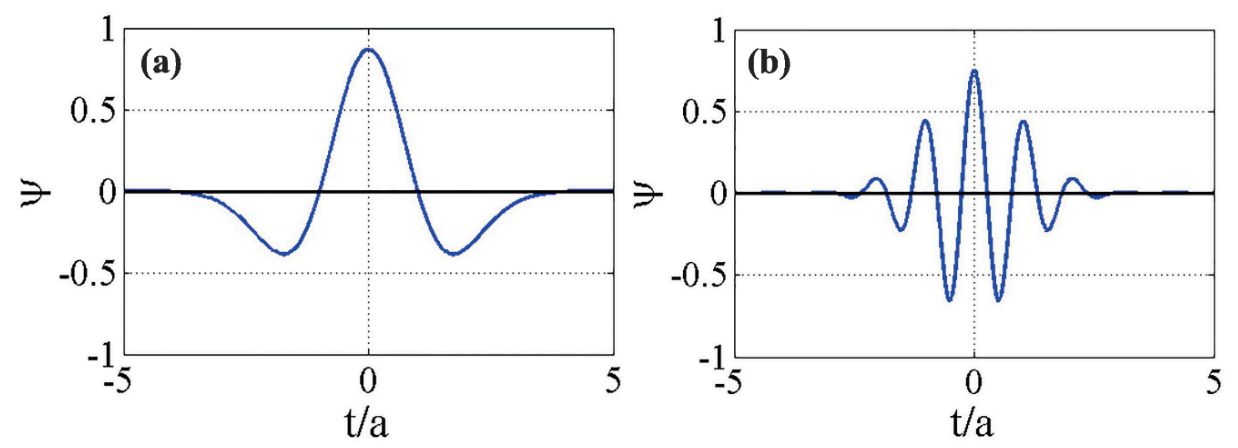

Figure 3. Shapes of the used wavelets adopting $a=1$ : (a) mother wavelet Mexican hat; (b) mother wavelet Morlet for $k_{M}=6$.

The other mother wavelet used in this work is the Gabor function, also known as Morlet. This is a sine wave that is windowed (i.e., multiplied point by point) by a Gaussian:

$$
\psi(t)=\pi^{-1 / 4} e^{-j k_{M} t} e^{-\frac{t^{2}}{2}}
$$

where the wavevector $k_{M}=6$ [37]. The shape of the Morlet wavelet is illustrated in Figure $3 \mathrm{~b}$.

As carried out for FT, a specific cut-off frequency will be applied to eliminate the disturbances in the high-frequency signals of $h$ through the adopted two wavelet functions.

\section{Results}

The time variations of hydraulic heads in the injection well, $h$, were deduced as a difference between the recorded values of pressure and the undisturbed hydraulic head. Afterwards, the raw values of $h$ were filtered by Fourier transform (FT) and two wavelet transforms (WTs), i.e., Mexican hat (Mexh) and Morlet (Morl). As suggested by Aristodemo et al. [18] in order to describe the present hydrodynamic process well and have a contained time to process the raw data, the experimental data sampled by the measurement frequency $f=100 \mathrm{~Hz}$ are taken into account. The smoothing methods to remove the high-frequency disturbance on $h$ were performed by tuning a particular cut-off frequency in the considered approaches. For the involved FT and WT cases, an independent setting value of $f_{c}=1.75 \mathrm{~Hz}$ was used to smooth out the high-frequency disturbance in the time series of $h$ due to specific environmental and electrical noise during the experiments. It can be highlighted that a specific choice of $f_{c}$ should be performed in each measurement campaign and for each used pressure sensor. Here, particular attention was addressed to choose a specific tuning of the cut-off frequency in all smoothing methods in order to preserve energy contributions in the time variation of $h$. For the processing phase, an interval of $50 \mathrm{~s}$ was taken into account for modeling the history of $h$. After the involved time window, the resulting variations of $h$ are less than $0.6 \%$ of the maximum value of hydraulic head.

\subsection{Modeling of Hydraulic Head Data}

The raw and smoothed time variations of $h$ were inspected to calculate the hydraulic conductivity of the porous media, i.e., model layouts I, II, III and IV, constituting the aquifer. For all slug volumes and for all model layouts, the first step was the fitting operation of the considered time variations of 
the hydraulic head through the exponential decay law represented by the Cooper's analytical solution (see Equation (1)) with the related boundary conditions. For the representative case given by model layout III and for $V=90 \mathrm{~mL}$, Figure 4 highlights the raw times series of $h$ (Figure 4a) and those filtered by FT (Figure 4b), Mexh (Figure 4c) and Morl (Figure 4d), the corresponding Cooper's solution and the $95 \%$ prediction bounds. Among the involved tests, the present case with $V=90 \mathrm{~mL}$ was chosen to underline the highest variation of $h$. The time $t=0$ is linked to the occurrence of the maximum value of $h$. By inspecting the results shown in Figure 4, the raw time variation of $h$ shows a significant high-frequency noise if compared to smoothed ones. With the aim of preserving the peak and the shape of $h$, the filtered time variations of $h$ with FT, Mexh and Morl show non-linear features characterized by small oscillations, particularly in the second part. With reference to the exponential fitting law, a general underestimation in the first part can be observed, followed by an overall overestimation in the second part. These non-linear effects were also noticed in the laboratory [18,52] and field (e.g., [53]) experimental conditions of slug tests. The above results show a different feature from the theoretical time series of $h$ by an energetic and frequency viewpoint. These particular characteristics refer to the difficulty of recovering the hypotheses of the Cooper's equation, i.e., homogeneous medium, Darcian flow, instantaneous slug injection and negligible well losses, even though controlled conditions were used (e.g., [1]). Indeed, the involved oscillations represent the result of combined effects like the manual introduction of a slug volume, the hydraulic losses in the well and the specific response of the groundwater.
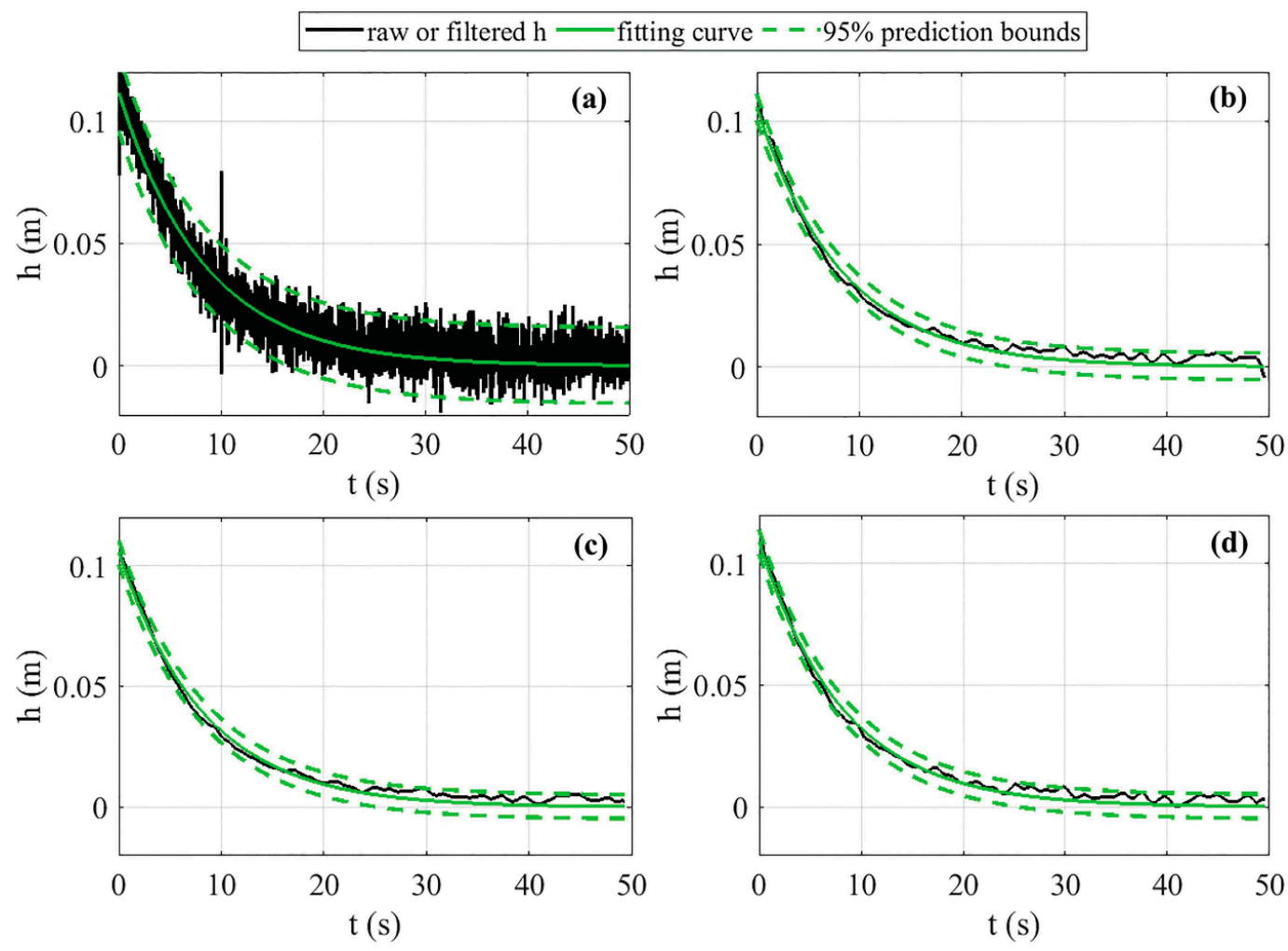

Figure 4. Time (s) series of raw and smoothed hydraulic heads $h(\mathrm{~m})$, fitting curves and $95 \%$ prediction bounds for $V=90 \mathrm{~mL}$ and model layout III. (a) raw, (b) Fourier transform (FT), (c) Mexh, (d) Morl.

To define the best processing method, limits and capabilities of raw and smoothed FT, Morl and Mexh hydraulic head data for the optimal fitting of the Cooper's equation (Equation (1)) using different model layouts were here treated by the determination of statistical parameters such as the correlation coefficient, $R^{2}$, and the relative error, se.

With reference to all involved raw and processed $h$, Table 3 shows $R^{2}$ as a function of slug volume, $V$, and for model layouts I, II, III and IV. In general, the mean values of $R^{2}$ generally tend to increase 
when higher slug volumes (from 70 to $90 \mathrm{~mL}$ ) are involved. Regarding the use of different porous media, the model layout I furnishes the highest values of $R^{2}$, followed by the model layouts IV, III and II. Moreover, we notice that the adopted smoothing approaches give higher values of $R^{2}$ compared to the use of raw $h$.

Table 3. Correlation coefficients $R^{2}$ vs. slug volumes $V(\mathrm{~mL})$, raw data and FT, Mexh and Morl smoothing methods for model layout I, II, III and IV.

\begin{tabular}{|c|c|c|c|c|c|c|c|c|c|c|}
\hline \multicolumn{11}{|c|}{$R^{2}$} \\
\hline & & $V(\mathrm{~mL})$ & & 30 & 40 & 50 & 60 & 70 & 80 & 90 \\
\hline \multirow{16}{*}{$\begin{array}{l}\text { Model } \\
\text { layout }\end{array}$} & \multirow{4}{*}{ I } & \multirow{4}{*}{ Smoothing technique } & raw & 0.519 & 0.672 & 0.841 & 0.907 & 0.925 & 0.915 & 0.912 \\
\hline & & & FT & 0.970 & 0.972 & 0.977 & 0.986 & 0.988 & 0.982 & 0.987 \\
\hline & & & Mexh & 0.977 & 0.978 & 0.980 & 0.988 & 0.990 & 0.984 & 0.989 \\
\hline & & & Morl & 0.968 & 0.973 & 0.977 & 0.985 & 0.988 & 0.980 & 0.990 \\
\hline & \multirow{4}{*}{ II } & \multirow{4}{*}{ Smoothing technique } & raw & - & - & 0.744 & 0.696 & 0.751 & 0.732 & 0.750 \\
\hline & & & FT & - & - & 0.790 & 0.794 & 0.832 & 0.790 & 0.821 \\
\hline & & & Mexh & - & - & 0.821 & 0.833 & 0.842 & 0.839 & 0.841 \\
\hline & & & Morl & - & - & 0.250 & 0.315 & 0.364 & 0.520 & 0.558 \\
\hline & \multirow{4}{*}{ III } & \multirow{4}{*}{ Smoothing technique } & raw & 0.502 & 0.604 & 0.537 & 0.803 & 0.847 & 0.835 & 0.910 \\
\hline & & & FT & 0.962 & 0.946 & 0.964 & 0.953 & 0.948 & 0.946 & 0.973 \\
\hline & & & Mexh & 0.971 & 0.958 & 0.966 & 0.955 & 0.948 & 0.948 & 0.977 \\
\hline & & & Morl & 0.796 & 0.766 & 0.813 & 0.766 & 0.758 & 0.718 & 0.803 \\
\hline & \multirow{4}{*}{ IV } & \multirow{4}{*}{ Smoothing technique } & raw & 0.582 & 0.613 & 0.698 & 0.766 & 0.765 & 0.833 & 0.776 \\
\hline & & & FT & 0.961 & 0.953 & 0.989 & 0.991 & 0.989 & 0.988 & 0.980 \\
\hline & & & Mexh & 0.977 & 0.961 & 0.992 & 0.992 & 0.993 & 0.994 & 0.981 \\
\hline & & & Morl & 0.852 & 0.817 & 0.867 & 0.869 & 0.873 & 0.852 & 0.857 \\
\hline
\end{tabular}

Among the used smoothing techniques and apart from one case (model layout I with $V=90$ $\mathrm{mL}$ ), Table 3 highlights that the Mexh wavelet furnishes the highest $R^{2}$, followed respectively by FT and Morl. The obtained results are consistent with the findings made by Aristodemo et al. [18] in which the involved time variation of $h$ is represented by an unsteady flow and better resembles the shape of the Mexican hat wavelet (see Figure 3a). Indeed, FT is based on periodic signals and, then, for phenomena that do not change in time, while the Morl wavelet is related to the occurrence of spurious "Gibbs-like" phenomena when rapid changes of hydraulic head appear in the time variation of $h$ (e.g., [33]). The superiority of the Mexh wavelet compared to Morl one was also underlined for other unsteady flow processes such as the impact of solitary waves on submerged circular cylinders [48] and for sloshing processes in water tanks [33].

For the other analyzed statistical parameter, i.e., se, Table 4 shows their values as a function of $V$ and the raw and smoothing data adopting the model layouts I, II, III and IV. The resulting values of se prove to be quite in agreement with those determined for $R^{2}$ (see Table 3). Apart from some cases where Morl is superior to the smoothing methods (i.e., one case for layout II and two cases for layout IV), the lowest values of se are linked to the use of Mexh to filter the initial raw time series of $h$, followed by smoothed FT and Morl data and raw ones, respectively. Regarding the different porous media involved in the experimental campaign, it is possible to notice that lowest se are related to the model layout III. Moreover, for layout I the lowest se refers to $V=70 \mathrm{~mL}$, for layout II to $50 \mathrm{~mL}$, for layout III to $40 \mathrm{~mL}$ and for layout IV to $80 \mathrm{~mL}$. In addition, a not well-defined trend is observed as a function of $V$ and the lowest se are linked to 30 and $50 \mathrm{~mL}$. On the basis of the results deduced from the statistical analyses on $R^{2}$ and se, the application of a Mexican hat wavelet to filter the raw time variation of $h$ leads to the best results in terms of $R^{2}$ (highest values) and se (lowest values). 
Table 4. Relative error se (m) vs. slug volumes $V(\mathrm{~mL})$, raw data and FT, Mexh and Morl smoothing methods for model layout I, II, III and IV.

\begin{tabular}{|c|c|c|c|c|c|c|c|c|c|c|}
\hline \multicolumn{11}{|c|}{$s e(\mathrm{~m})$} \\
\hline & & $V(\mathrm{~mL})$ & & 30 & 40 & 50 & 60 & 70 & 80 & 90 \\
\hline \multirow{16}{*}{$\begin{array}{l}\text { Model } \\
\text { layout }\end{array}$} & \multirow{4}{*}{ I } & \multirow{4}{*}{$\begin{array}{l}\text { Smoothing } \\
\text { technique }\end{array}$} & raw & $1.11 \times 10^{-4}$ & $1.14 \times 10^{-4}$ & $9.67 \times 10^{-5}$ & $7.71 \times 10^{-5}$ & $7.58 \times 10^{-5}$ & $9.65 \times 10^{-5}$ & $1.09 \times 10^{-4}$ \\
\hline & & & FT & $1.80 \times 10^{-5}$ & $2.4 \times 10^{-5}$ & $3.20 \times 10^{-5}$ & $2.30 \times 10^{-5}$ & $2.37 \times 10^{-5}$ & $3.56 \times 10^{-5}$ & $3.36 \times 10^{-5}$ \\
\hline & & & Mexh & $1.56 \times 10^{-5}$ & $2.10 \times 10^{-5}$ & $2.96 \times 10^{-5}$ & $2.11 \times 10^{-5}$ & $2.18 \times 10^{-5}$ & $3.28 \times 10^{-5}$ & $3.04 \times 10^{-5}$ \\
\hline & & & Morl & $1.86 \times 10^{-5}$ & $2.52 \times 10^{-5}$ & $3.26 \times 10^{-5}$ & $2.40 \times 10^{-5}$ & $2.37 \times 10^{-5}$ & $3.69 \times 10^{-5}$ & $3.09 \times 10^{-5}$ \\
\hline & \multirow{4}{*}{ II } & \multirow{4}{*}{$\begin{array}{l}\text { Smoothing } \\
\text { technique }\end{array}$} & raw & - & - & $1.09 \times 10^{-4}$ & $1.51 \times 10^{-4}$ & $1.23 \times 10^{-4}$ & $1.89 \times 10^{-4}$ & $1.74 \times 10^{-4}$ \\
\hline & & & FT & - & - & $8.58 \times 10^{-5}$ & $1.14 \times 10^{-4}$ & $1.09 \times 10^{-4}$ & $1.57 \times 10^{-4}$ & $1.34 \times 10^{-4}$ \\
\hline & & & Mexh & - & - & $7.90 \times 10^{-5}$ & $9.99 \times 10^{-5}$ & $9.70 \times 10^{-5}$ & $1.29 \times 10^{-4}$ & $1.20 \times 10^{-4}$ \\
\hline & & & Morl & - & - & $1.37 \times 10^{-4}$ & $1.52 \times 10^{-4}$ & $1.55 \times 10^{-4}$ & $2.00 \times 10^{-4}$ & $1.72 \times 10^{-4}$ \\
\hline & \multirow{4}{*}{ III } & \multirow{4}{*}{$\begin{array}{l}\text { Smoothing } \\
\text { technique }\end{array}$} & raw & $4.96 \times 10^{-5}$ & $5.19 \times 10^{-5}$ & $6.07 \times 10^{-5}$ & $4.89 \times 10^{-5}$ & $4.62 \times 10^{-5}$ & $5.37 \times 10^{-5}$ & $5.28 \times 10^{-5}$ \\
\hline & & & FT & $5.07 \times 10^{-5}$ & $1.15 \times 10^{-5}$ & $1.39 \times 10^{-5}$ & $1.49 \times 10^{-5}$ & $1.74 \times 10^{-5}$ & $1.92 \times 10^{-5}$ & $2.21 \times 10^{-5}$ \\
\hline & & & Mexh & $8.25 \times 10^{-6}$ & $1.03 \times 10^{-5}$ & $1.22 \times 10^{-5}$ & $1.45 \times 10^{-5}$ & $1.72 \times 10^{-5}$ & $1.86 \times 10^{-5}$ & $2.03 \times 10^{-5}$ \\
\hline & & & Morl & $1.99 \times 10^{-5}$ & $2.48 \times 10^{-5}$ & $2.95 \times 10^{-5}$ & $3.50 \times 10^{-5}$ & $4.15 \times 10^{-5}$ & $4.64 \times 10^{-5}$ & $5.76 \times 10^{-5}$ \\
\hline & \multirow{4}{*}{ IV } & \multirow{4}{*}{$\begin{array}{l}\text { Smoothing } \\
\text { technique }\end{array}$} & raw & $4.97 \times 10^{-5}$ & $2.48 \times 10^{-5}$ & $4.99 \times 10^{-5}$ & $5.00 \times 10^{-5}$ & $5.48 \times 10^{-5}$ & $5.18 \times 10^{-5}$ & $1.43 \times 10^{-5}$ \\
\hline & & & FT & $4.62 \times 10^{-5}$ & $2.48 \times 10^{-5}$ & $7.22 \times 10^{-5}$ & $8.74 \times 10^{-5}$ & $1.01 \times 10^{-4}$ & $1.19 \times 10^{-5}$ & $1.20 \times 10^{-5}$ \\
\hline & & & Mexh & $5.97 \times 10^{-6}$ & $2.48 \times 10^{-5}$ & $5.98 \times 10^{-6}$ & $8.59 \times 10^{-5}$ & $9.78 \times 10^{-5}$ & $8.22 \times 10^{-6}$ & $1.47 \times 10^{-5}$ \\
\hline & & & Morl & $1.69 \times 10^{-5}$ & $2.48 \times 10^{-5}$ & $2.46 \times 10^{-5}$ & $3.00 \times 10^{-5}$ & $3.46 \times 10^{-5}$ & $3.84 \times 10^{-5}$ & $4.28 \times 10^{-5}$ \\
\hline
\end{tabular}


For the representative case related to the model layout III and for $V=90 \mathrm{~mL}$, Figure 5 describes the wavelet coefficients, $\Psi$, given by the use of the Mexican hat wavelet. The values of $\Psi$ are linked to the energy contributions appearing in the time-frequency domain of the raw hydraulic heads. To highlight the operation of smoothing of the high-frequency disturbance in the raw time variation of $h$, the horizontal dashed black line in the wavelet plane represents the cut-off frequency, $f_{c}$. The peak frequencies, $f_{p}$, linked to the maximum values of $\Psi$ for each frequency $f$, are overlapped on the wavelet coefficients in Figure 5 and plotted through white dots. As it is possible to notice, high positive wavelet coefficients mean high correlation between the raw values of $h$ and the wavelet function for a certain value of $f$. On the other hand, high negative values of $\Psi$ mean that the hydraulic head data are negatively correlated with the wavelet. In other words, the input signal and the wavelet result in anti-phase.

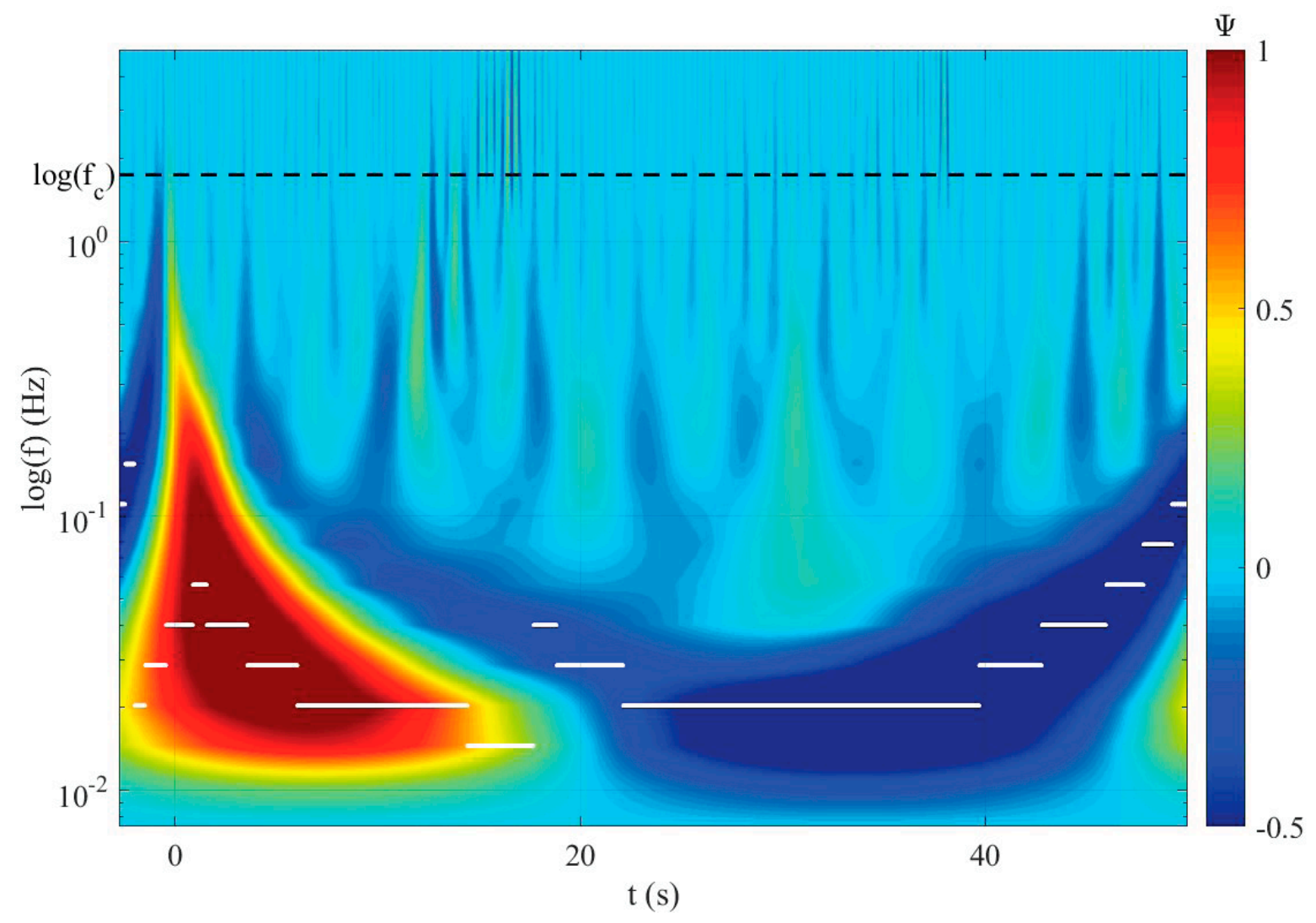

Figure 5. Wavelet coefficients $\Psi$ and peak frequencies $f_{p}(\mathrm{~Hz})$ (white dots) of the filtered time (s) series of hydraulic head $h(\mathrm{~m})$ by Mexican hat wavelet for $V=90 \mathrm{~mL}$ and model layout III.

Coefficients close to 0 occur when there is a slight correlation between the wavelet and the signal, meaning that the signal contains a very low energy at the corresponding frequency. This is the case of the appearing of high-frequency disturbance, as shown in Figure 5 for $f>f_{c}$.

Figure 6 describes the features of the smoothed $h$ given by the application of the Mexh wavelet. The analysis is carried out by plotting the wavelet coefficients corresponding to the mean energy and the mean frequency oscillations around Cooper's solution. Specifically, Figure 6a highlights the ratio $\Psi_{\max , m, h} / \Psi_{\max , h}$, where $\Psi_{\max , m, h}$ is the mean value of maximum wavelet coefficients on $h$ and $\Psi_{\max , h}$ is the maximum value among the maximum wavelet coefficients on $h$. The above ratio oscillates from about 0.4 to 1 that correspond to 30 and $90 \mathrm{~mL}$, respectively. It can be observed that higher ratios are related to higher $V$ and to model layouts I and II. Larger differences on model layouts are linked to intermediate slug volumes, i.e., $50<V<70 \mathrm{~mL}$. Figure $6 \mathrm{~b}$ highlights the features of the mean peak frequency, $f_{p m, h}$, vs. $V$ and model layouts. The variation of the values of $f_{p m, h}$ over $V$ shows a small 
decrease and appears in a frequency band ranging from approximately 0.024 to $0.038 \mathrm{~Hz}$. The above frequency range is related to the appearance of long oscillations around the theoretical curve of Cooper et al. [9] with corresponding wave periods varying between approximately 26 and $42 \mathrm{~s}$. It is interesting to notice that the mean peak frequencies associated to the different model layouts show a specific trend. In particular, from model layout I to IV the frequency oscillation tends to increase. Indeed, for model layout I a unique great oscillation occurs for the time interval of the involved slug tests. Conversely, about two oscillations appear for model layout IV.

(a)
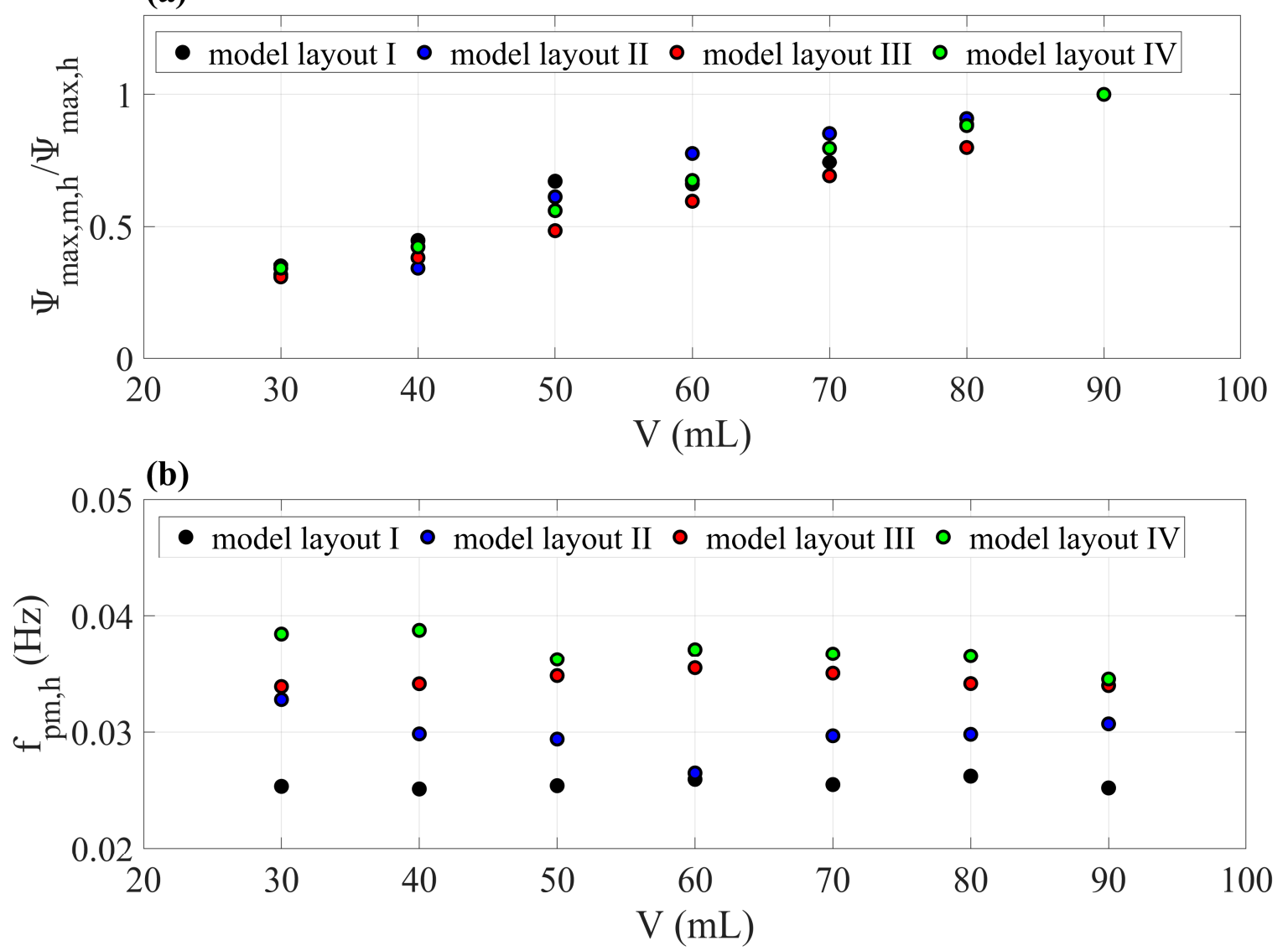

Figure 6. (a) Ratio between mean value of maximum wavelet coefficients, $\Psi_{\max , m, h}$, and maximum value of maximum wavelet coefficients, $\Psi_{\max , h}$, for various slug volumes $V(\mathrm{~mL})$ and model layouts $\mathrm{I}$, II, III and IV; (b) mean peak frequency, $f_{p m, h}(\mathrm{~Hz})$ for various slug volumes $V(\mathrm{~mL})$ and model layouts I, II, III and IV.

\subsection{Evaluation of Hydraulic Conductivity}

Table 5 shows the values of $k$ deduced from the method of Cooper et al. [9] using the Equation (1) and verifying the achievement of the initial and boundary conditions by checking hydraulic heads in observation wells. For all slug volumes $V$ and for the model layouts I, II, III and IV, the results obtained are linked to the use of raw and smoothed (FT, Mexh and Morl) values of $h$. By inspecting the resulting values of $k$ over the slug volumes, a general small variation of the hydraulic conductivity for each model layout can be noticed. Compared to other experiments reported in the literature $[1,19]$, this aspect leads to good acquired data quality, particularly for the smoothed $h$. For model layout $\mathrm{I}$, an increase of $k$ proportionally to $V$ can be observed, while this trend was not noticed for other model layouts. Regarding the feature of $k$ related to the adopted model layouts, an increase of the hydraulic conductivity is evident from model layout I to model layout IV and occurs both for raw and for smoothed values of $h$. 
Table 5. Hydraulic conductivities $k(\mathrm{~m} / \mathrm{s})$ vs. slug volumes $V(\mathrm{~mL})$, raw data and FT, Mexh and Morl smoothing methods for model layout I, II, III and IV.

\begin{tabular}{|c|c|c|c|c|c|c|c|c|}
\hline \multicolumn{9}{|c|}{$k(\mathrm{~m} / \mathrm{s})$} \\
\hline \multirow{2}{*}{$\begin{array}{l}\text { Smoothing } \\
\text { Technique }\end{array}$} & \multirow{2}{*}{ Model Layout } & \multicolumn{7}{|c|}{$V(\mathrm{~mL})$} \\
\hline & & 30 & 40 & 50 & 60 & 70 & 80 & 90 \\
\hline \multirow{4}{*}{ Raw data } & I & $7.16 \times 10^{-5}$ & $7.74 \times 10^{-5}$ & $4.88 \times 10^{-5}$ & $1.06 \times 10^{-4}$ & $8.47 \times 10^{-5}$ & $1.44 \times 10^{-4}$ & $1.50 \times 10^{-4}$ \\
\hline & II & - & - & $3.71 \times 10^{-4}$ & $6.80 \times 10^{-4}$ & $6.28 \times 10^{-4}$ & $3.96 \times 10^{-4}$ & $2.73 \times 10^{-4}$ \\
\hline & III & $6.20 \times 10^{-4}$ & $6.47 \times 10^{-4}$ & $6.82 \times 10^{-4}$ & $8.04 \times 10^{-4}$ & $6.81 \times 10^{-4}$ & $6.92 \times 10^{-4}$ & $7.27 \times 10^{-4}$ \\
\hline & IV & $1.05 \times 10^{-3}$ & $1.01 \times 10^{-3}$ & $1.98 \times 10^{-3}$ & $1.74 \times 10^{-3}$ & $1.23 \times 10^{-3}$ & $1.72 \times 10^{-3}$ & $1.44 \times 10^{-3}$ \\
\hline \multirow{4}{*}{$\begin{array}{l}\text { Fourier } \\
\text { Transform }\end{array}$} & I & $1.84 \times 10^{-4}$ & $3.21 \times 10^{-4}$ & $1.66 \times 10^{-4}$ & $2.38 \times 10^{-4}$ & $3.04 \times 10^{-4}$ & $2.35 \times 10^{-4}$ & $2.42 \times 10^{-4}$ \\
\hline & II & - & - & $2.66 \times 10^{-4}$ & $4.16 \times 10^{-4}$ & $4.08 \times 10^{-4}$ & $4.02 \times 10^{-4}$ & $3.15 \times 10^{-4}$ \\
\hline & III & $6.41 \times 10^{-4}$ & $7.36 \times 10^{-4}$ & $6.62 \times 10^{-4}$ & $6.75 \times 10^{-4}$ & $7.84 \times 10^{-4}$ & $6.73 \times 10^{-4}$ & $7.45 \times 10^{-4}$ \\
\hline & IV & $1.17 \times 10^{-3}$ & $9.50 \times 10^{-4}$ & $1.14 \times 10^{-3}$ & $1.13 \times 10^{-3}$ & $1.16 \times 10^{-3}$ & $1.42 \times 10^{-3}$ & $1.31 \times 10^{-3}$ \\
\hline \multirow{4}{*}{$\begin{array}{c}\text { Mexican hat } \\
\text { Wavelet }\end{array}$} & I & $2.15 \times 10^{-4}$ & $2.96 \times 10^{-4}$ & $1.15 \times 10^{-4}$ & $2.79 \times 10^{-4}$ & $3.13 \times 10^{-4}$ & $2.38 \times 10^{-4}$ & $2.88 \times 10^{-4}$ \\
\hline & II & - & - & $2.36 \times 10^{-4}$ & $2.60 \times 10^{-4}$ & $3.61 \times 10^{-4}$ & $2.98 \times 10^{-4}$ & $3.10 \times 10^{-4}$ \\
\hline & III & $7.49 \times 10^{-4}$ & $6.67 \times 10^{-4}$ & $7.15 \times 10^{-4}$ & $8.14 \times 10^{-4}$ & $7.53 \times 10^{-4}$ & $7.36 \times 10^{-4}$ & $7.86 \times 10^{-4}$ \\
\hline & IV & $1.07 \times 10^{-3}$ & $1.02 \times 10^{-3}$ & $1.09 \times 10^{-3}$ & $1.30 \times 10^{-3}$ & $1.31 \times 10^{-3}$ & $1.31 \times 10^{-3}$ & $1.34 \times 10^{-3}$ \\
\hline \multirow{4}{*}{ Morlet Wavelet } & I & $1.89 \times 10^{-4}$ & $3.48 \times 10^{-4}$ & $1.79 \times 10^{-4}$ & $2.44 \times 10^{-4}$ & $3.16 \times 10^{-4}$ & $2.40 \times 10^{-4}$ & $2.78 \times 10^{-4}$ \\
\hline & II & - & - & $4.44 \times 10^{-4}$ & $5.14 \times 10^{-4}$ & $4.06 \times 10^{-4}$ & $5.47 \times 10^{-4}$ & $5.42 \times 10^{-4}$ \\
\hline & III & $7.52 \times 10^{-4}$ & $8.30 \times 10^{-4}$ & $8.40 \times 10^{-4}$ & $1.08 \times 10^{-3}$ & $1.00 \times 10^{-3}$ & $7.69 \times 10^{-4}$ & $8.19 \times 10^{-4}$ \\
\hline & IV & $8.15 \times 10^{-4}$ & $7.64 \times 10^{-4}$ & $1.13 \times 10^{-3}$ & $1.30 \times 10^{-3}$ & $1.36 \times 10^{-3}$ & $1.44 \times 10^{-3}$ & $1.56 \times 10^{-3}$ \\
\hline
\end{tabular}


To analyze the tendency of $k$ using the raw and smoothed data sets, Figure 7 describes the relative error, se, with respect to the mean value of hydraulic conductivity, $k_{m}$. For all model layouts, it is possible to notice that the values of $k$ deduced from the smoothed $h$ with the Mexican hat wavelet give the lowest values of se. Specifically, using Mexh the values of se range from $0.08 \times 10^{-4} \mathrm{~m}$ to $0.5 \times 10^{-4}$ $\mathrm{m}$, with the lowest values and less variability associated with the model layout I. The results obtained are consistent with that determined in Section 4.1 on the statistical analyses on the hydraulic heads.

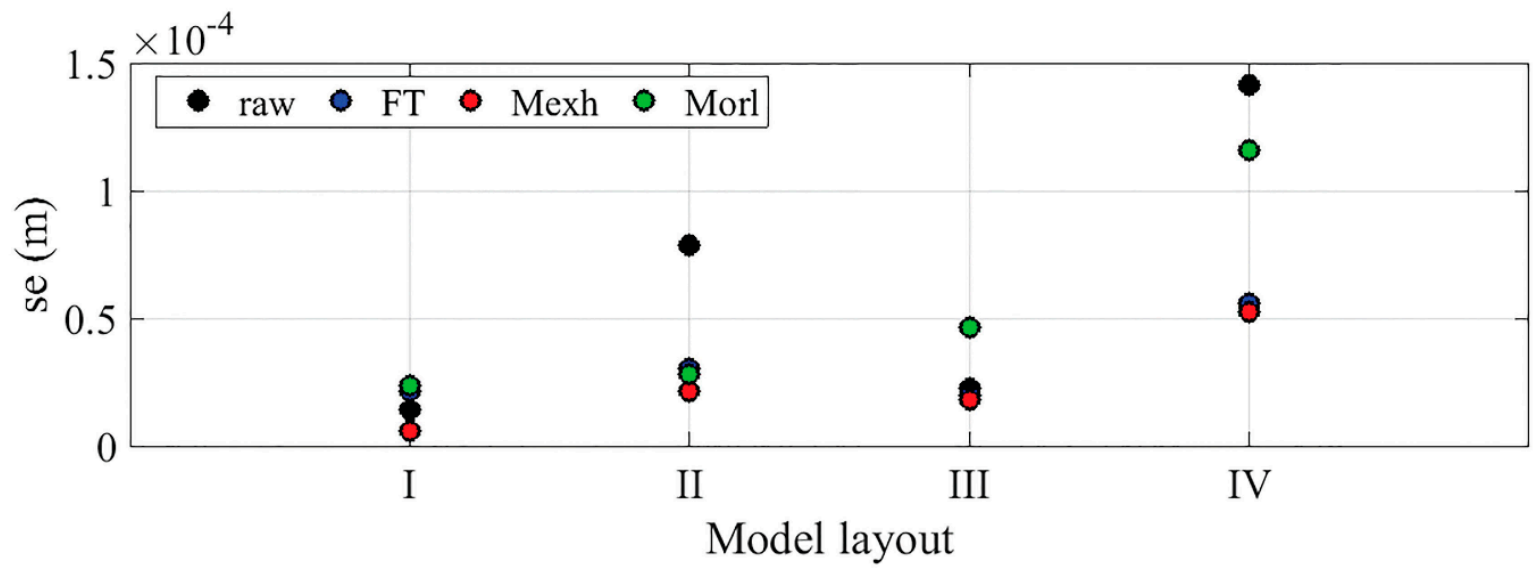

Figure 7. Relative error se $(\mathrm{m})$ with respect to the mean hydraulic conductivities $k_{m}(\mathrm{~m} / \mathrm{s})$ obtained by raw data and FT, Mexh and Morl smoothed data and model layouts I, II, III and IV.

\section{Conclusions}

An experimental investigation at laboratory scale executed on a 3D physical model was carried out to study the hydraulic response of an aquifer by means of slug tests. During the experimental campaign, four different kinds of porous media characterizing the saturated layer of the aquifer were considered. In order to give useful information on the characteristics of the aquifer, a smoothing analysis of the recorder raw hydraulic heads was performed. Specifically, methods working in frequency and time-frequency domains such as Fourier and wavelet transforms were applied to eliminate the unwanted high-frequency disturbances in the time variation of $h$. Limits and capabilities of the involved smoothing approaches were inspected by comparing the obtained smoothed $h$ with the reference Cooper's solution. By changing the injected slug volume and the porous medium of the aquifer, it was observed, along the lines of the previous work by Aristodemo et al. [18], that the Mexh wavelet is superior to the other methods (FT and Morl wavelet) for the analyzed statistical parameters, i.e., correlation coefficient and relative error. The above finding proves to be consistent with the form of the time variation of hydraulic head which is similar to the mother wavelet Mexican hat compared to the other forms. Energy contents and frequency oscillations derived by the use of the Mexh wavelet were investigated, showing that the energy contents generally tend to increase when the slug volume increases and the peak frequency tends to increase from model layout I to IV. This means that a unique oscillation occurs in the time interval of the variation of $h$ for model layout I involved, while about two wave periods occurs when model layout IV is adopted. The raw and smoothed data sets were used to determine the hydraulic conductivity of the porous media constituting the aquifer. The Mexh wavelet leads to more stable values of $k$ if compared with the other smoothing approaches.

This work highlights that a careful smoothing analysis is certainly very useful when the data sets obtained by slug tests are very large. Useful indications are given on the most appropriate smoothing method to be used.

It is certain that the results obtained with the present experimental study remain valid for laboratory conditions and cannot be extended to field conditions without the appropriate checks. Therefore, an increase in field investigations is considered necessary to verify the possibility to extend to larger scales than the laboratory the validity of the results obtained in the present study. 
Author Contributions: C.F. conceived and designed the experiments; A.L. and G.T. performed the experiments; F.A. performed the smoothing analysis; F.A. and C.F. wrote the paper; and M.F.R.-V. supervised the research.

Funding: This research received no external funding.

Conflicts of Interest: The authors declare no conflict of interest.

\section{References}

1. Butler, J.J., Jr. The Design, Performance, and Analysis of Slug Tests; Lewis Publishers: Boca Raton, FL, USA, 1997.

2. Beckie, R.; Harvey, C.F. What does a slug test measure: An investigation of instrument response and the effects of heterogeneity. Water Resour. Res. 2002, 38, 1290. [CrossRef]

3. Zurbuchen, B.R.; Zlotnik, V.A.; Butler, J.J., Jr. Dynamic interpretation of slug tests in highly permeable aquifers. Water Resour. Res. 2002, 38, 7-1-7-18. [CrossRef]

4. Dietrich, P.; Butler, J.J., Jr.; Faiß, K. A Rapid Method for Hydraulic Profiling in Unconsolidated Formations. Ground Water 2008, 46, 323-328. [CrossRef] [PubMed]

5. Chiasson, P. Interpretation of Falling-Head Tests in Presence of Random Measurement Error. ISRN Civ. Eng. 2012, 2012, 1-10. [CrossRef]

6. Severino, G.; De Bartolo, S.; Toraldo, G.; Gowri, S.; Hari, V. Travel Time Approach to Kinetically Sorbing Solute by Diverging Radial Flows through Heterogeneous Porous Formations. Water Resour. Res. 2012, 48, W12527. [CrossRef]

7. Lewis, M. A Comparative Analysis of Two Slug Test Methods in Puget Lowland Glacio-Fluvial Sediments near Coupeville, WA; Report for the Degree of Masters of Earth and Space Science: Applied Geosciences; University of Washington: Seattle, WA, USA, 2013.

8. Hvorslev, J.M. Time Lag and Soil Permeability in Ground-Water Observations; Bull. 36; U.S. Corps of Engineers, Waterways Experiment Station: Vicksburg, MS, USA, 1951; pp. 1-50.

9. Cooper, H.H., Jr.; Bredehoeft, J.D.; Papadopulos, I.S. Response of a Finite-Diameter Well to an Instantaneous Charge Water. Water Resour. Res. 1967, 3, 263-269. [CrossRef]

10. Bouwer, H.; Rice, R.C. A Slug test for determining hydraulic conductivity of unconfined aquifers with completely or partially penetrating wells. Water Resour. Res. 1976, 12, 423-428. [CrossRef]

11. ASTM Standard D4044, Standard Test Method (Field Procedure) for Instantaneous Change in Head (Slug) tests for Determining Hydraulic Properties of Aquifers. In Annual Book of ASTM Standards; 04.08; ASTM International: West Conshohocken, PA, USA, 2006.

12. Swamee, P.K.; Singh, S.K. Estimating storage coefficient and transmissivity from slug test data. J. Irrig. Drain. Eng. 2007, 133, 505-507. [CrossRef]

13. Koussis, A.D.; Akylas, E. Slug Test in Confined Aquifers, the Over-Damped Case: Quasi-Steady Flow Analysis. Ground Water 2011, 50, 608-613. [CrossRef]

14. Yang, S.Y.; Yeh, H.D. A Simple Approach Using Bouwer and Rice's Method for Slug Test Data Analysis. Ground Water 2004, 42, 781-784. [CrossRef]

15. Cardiff, M.; Barrash, W.; Thoma, M.; Malama, B. Information content of slug tests for estimating hydraulic properties in realistic, high-conductivity aquifer scenarios. J. Hydrol. 2011, 403, 66-82. [CrossRef]

16. Chapuis, R.P. Interpreting Slug Tests with Large Data Sets. Geotech. Test. J. 2009, 32, 139-146.

17. Abellan, A.; Noetinger, B. Optimizing subsurface field data acquisition using information theory. Math. Geosci. 2010, 42, 603-630. [CrossRef]

18. Aristodemo, F.; Ianchello, M.; Fallico, C. Smoothing analysis of slug tests data for aquifer characterization at laboratory scale. J. Hydrol. 2018, 562, 125-139. [CrossRef]

19. Butler, J.J., Jr.; McElwee, C.D.; Wenzhi, L. Improving the quality of parameter estimates obtained from slug tests. Ground Water 1996, 34, 480-490. [CrossRef]

20. Phillips, G.R.; Harris, J.M. Predicting the Statistical Properties of Least-Squares Polynomial Filters. Anal. Chem. 1990, 62, 2749-2752. [CrossRef]

21. Box, G.E.P.; Jenkins, G.M. Time Series Analysis: Forecasting and Control; Holden-Day: San Francisco, CA, USA, 1970.

22. Desbarats, A.J. Spatial averaging of hydraulic conductivity under radial flow conditions. Math. Geol. 1994, 26, 1-21. [CrossRef] 
23. Beckie, R. Measurement scale, network sampling scale, and groundwater model parameters. Water Resour. Res. 1996, 32, 65-76. [CrossRef]

24. Long, A.J.; Derickson, R.G. Linear systems analysis in a karst aquifer. J. Hydrol. 1999, 219, 206-217. [CrossRef]

25. Manga, M. On the timescales characterizing groundwater discharge at springs. J. Hydrol. 1999, $219,56-69$. [CrossRef]

26. Comaniciu, D.; Meer, P. Mean Shift: A Robust Approach toward Feature Space Analysis. IEEE Trans. Pattern Anal. 2002, 24, 603-619. [CrossRef]

27. Schmidt, K.S.; Skidmore, A.K. Smoothing vegetation spectra with wavelets. Int. J. Remote Sens. 2004, 25, 1167-1184. [CrossRef]

28. Audouin, O.; Bodin, J. Analysis of slug-tests with high-frequency oscillations. J. Hydrol. 2007, 334, $282-289$. [CrossRef]

29. Browne, M.; Mayer, N.; Cutmore, T.R.H. A multiscale polynomial filter for adaptive smoothing. Digit. Signal Process. 2007, 17, 69-75. [CrossRef]

30. Cirpka, O.A.; Fienen, M.N.; Hofer, M.; Hoehn, E.; Tessarini, A.; Kipfer, R.; Kitanidis, P.K. Analyzing bank filtration by deconvoluting time series of electric conductivity. Ground Water 2007, 45, 318-328. [CrossRef]

31. Damiani, L.; Vicinanza, D.; Aristodemo, F.; Saponieri, A.; Corvaro, S. Experimental investigation on wave set up and nearshore velocity field in presence of a BDS. J. Coast. Res. 2011, 64, 55-59.

32. Jiménez-Martinez, J.; Longuevergne, L.; Le Borgne, T.; Davy, P.; Russian, A.; Bour, O. Temporal and spatial scaling of hydraulic response to recharge in fractured aquifers: Insights from a frequency domain analysis. Water Resour. Res. 2013, 49, 3007-3023. [CrossRef]

33. Meringolo, D.D.; Colagrossi, A.; Marrone, S.; Aristodemo, F. On the filtering of acoustic components in weakly-compressible SPH simulations. J. Fluids Struct. 2017, 70, 1-23. [CrossRef]

34. Viovy, N.; Arino, O.; Belward, A. The Best Index Slope Extraction (BISE): A method for reducing noise in NDVI time-series. Int. J. Remote Sens. 1992, 13, 1585-1590. [CrossRef]

35. Ruffin, C.; King, R.L.; Younan, N.H. A Combined Derivative Spectroscopy and Savitzky-Golay Filtering Method for the Analysis of Hyperspectral Data. GIsci. Remote Sens. 2008, 45, 1-15. [CrossRef]

36. Cooley, J.W.; Tukey, J.W. An algorithm for the machine calculation of complex Fourier series. Math. Comput. 1965, 19, 297-301. [CrossRef]

37. Torrence, C.; Compo, G.P. A practical guide to wavelet analysis. Bull. Am. Meteorol. Soc. 1998, 79, 61-78. [CrossRef]

38. Feitosa, G.S.; Chu, L.; Thompson, L.G.; Reynolds, A.C. Determination of permeability distribution from well-test pressure data. J. Petrol. Technol. 1994, 46, 607-615. [CrossRef]

39. Gautier, Y.; Nœtinger, B. Geostatistical parameters estimation using well test data. Oil Gas Sci. Technol. 2004, 59, 167-183. [CrossRef]

40. Tripepi, G.; Aristodemo, F.; Veltri, P.; Pace, C.; Solano, A.; Giordano, C. Experimental and numerical investigation of tsunami-like waves on horizontal circular cylinders. In Proceedings of the 36th International Conference on Ocean, Offshore and Arctic Engineering, Trondheim, Norway, 25-30 June 2017; pp. 1-10.

41. Calomino, F.; Alfonsi, G.; Gaudio, R.; D’Ippolito, A.; Lauria, A.; Tafarojnoruz, A.; Artese, S. Experimental and Numerical Study of Free-Surface Flows in a Corrugated Pipe. Water 2018, 10, 638. [CrossRef]

42. Papadopulos, I.S.; Bredehoeft, J.D.; Cooper, H.H. On the analysis of "Slug Test" data. Water Resour. Res. 1973, 9, 1087-1089. [CrossRef]

43. Bredehoeft, J.D.; Papadopulos, S.S. A Method for Determining the Hydraulic Properties of Tight Formations. Water Resour. Res. 1980, 16, 233-238. [CrossRef]

44. Chapuis, R.P. Overdamped slug test in monitoring wells: Review of interpretation methods with mathematical, physical, and numerical analysis of storativity influence. Can. Geotech. J. 1998, 35, 697-719. [CrossRef]

45. Gabor, D. Theory of communication. J. Inst. Electr Eng. 1946, 93, 429-457. [CrossRef]

46. Meringolo, D.D. Weakly-Compressible SPH Modeling of Fluid-Structure Interaction Problems. Ph.D. Thesis, University of Calabria, Rende, Italy, 2016; pp. 1-158.

47. Chui, C.K. An Introduction to Wavelet; Academic Press: New York, NY, USA, 1992; pp. 1-266.

48. Aristodemo, F.; Tripepi, G.; Meringolo, D.D.; Veltri, P. Solitary wave-induced forces on horizontal circular cylinders: Laboratory experiments and SPH simulations. Coast. Eng. 2017, 129, 17-35. [CrossRef]

49. Farge, M. Wavelet transforms and their applications to turbulence. Annu. Rev. Fluid Mech. 1992, 24, $395-457$. [CrossRef] 
50. Meyers, S.D.; Kelly, B.G.; O’Brien, J.J. An introduction to wavelet analysis in oceanography and meteorology: With application to the dispersion of Yanai waves. Mon. Weather Rev. 1993, 121, 2858-2866. [CrossRef]

51. Liu, P.C. Wavelet spectrum analysis and ocean wind waves. In Wavelets in Geophysics; Foufoula-Georgiou, E., Kumar, P., Eds.; Academic Press: New York, NY, USA, 1994; pp. 151-166.

52. Baptiste, N.; Chapuis, P.R. What maximum permeability can be measured with the monitoring well? Eng. Geol. 2015, 184, 111-118. [CrossRef]

53. McElwee, C.D. Improving the analysis of slug tests. J. Hydrol. 2002, 269, 122-133. [CrossRef]

(C) 2019 by the authors. Licensee MDPI, Basel, Switzerland. This article is an open access article distributed under the terms and conditions of the Creative Commons Attribution (CC BY) license (http://creativecommons.org/licenses/by/4.0/). 